\title{
What Time-Travel Teaches Us about Future-Bias
}

\author{
Kristie Miller (D)
}

check for

updates

Citation: Miller, K. What

Time-Travel Teaches Us about

Future-Bias. Philosophies 2021, 6, 38.

https://doi.org/10.3390/

philosophies6020038

Academic Editor: Alasdair Richmond

Received: 17 March 2021

Accepted: 28 April 2021

Published: 10 May 2021

Publisher's Note: MDPI stays neutral with regard to jurisdictional claims in published maps and institutional affiliations.

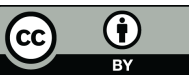

Copyright: (C) 2021 by the author. Licensee MDPI, Basel, Switzerland. This article is an open access article distributed under the terms and conditions of the Creative Commons Attribution (CC BY) license (https:/ / creativecommons.org/licenses/by/ $4.0 /)$.
Department of Philosophy, University of Sydney, Sydney, NSW 2006, Australia; kristie.miller@sydney.edu.au

\begin{abstract}
Future-biased individuals systematically prefer positively valenced events to be in the future (positive future-bias) and negatively valenced events to be in the past (negative future-bias). The most extreme form of future-bias is absolute future-bias, whereby we completely discount the value of past events when forming our preferences. Various authors have thought that we are absolutely future-biased and that future-bias (absolute or otherwise) is at least rationally permissible. The permissibility of future-bias is often held to be grounded in the structure of the temporal dimension. In this paper I consider several proposals for grounding the permissibility of such preferences and evaluate these in the light of the preferences we would have, and judge that we should have, in various time-travel scenarios. I argue that what we learn by considering these scenarios is that these preferences really have nothing to do with temporal structure. So, if something grounds their permissibility, it is not temporal structure.
\end{abstract}

Keywords: time travel; future-bias; temporal preferences

\section{Introduction}

Let us say that an agent is apparently time-biased with respect to some event ${ }^{1}$ just in case they have a preference for where in time that event is located. An agent is time-biased if, roughly, their preference for where in time some event is located is sensitive to their representation of its temporal location. So, an agent is time-biased if, with respect to two events $E$ and $E^{*}$ which are equally valuable to the self that experiences them, and adjusting for the subjective probabilities of the events occurring, the agent prefers one event to the other in virtue the temporal locations of the events. So, for instance, suppose that Annie the labradoodle prefers to eat liver cake now, rather than later. That preference might be the result of her believing that the liver cake will get progressively staler throughout the day, and hence that the liver cake later will be intrinsically less valuable to her future self than the liver cake now is to her present self; or it might be the result of her believing that someone else will likely eat the liver cake during the day if she does not eat it now, so she thinks that the probability of receiving the liver cake is higher now, than later; or it might be because she has been told that she will receive a giant turkey drumstick if she prefers to eat the liver cake now, rather than later. If reasons such as these are the sole reasons that Annie has the preference she does, I will say she is merely apparently time-biased. She does not discount the value of the later liver-cake because it is later, she discounts its value because it is intrinsically less valuable later, or because it is less certain later, or because there is something else of value that she will receive if she chooses to eat the liver cake earlier rather than later.

One kind of time-bias is future-bias. An agent is apparently future-biased if she prefers that positively valenced events be located in her future, and negatively valenced events be located in her past. An agent is in fact positively future-biased if with respect to two positively valenced events $E$ and $E^{*}$, where $E$ is located in the future, and $E^{*}$ is located in the past, and where $E$ and $E^{*}$ are equally valuable to the self that experiences them, and adjusting for

1 In what follows we will talk of the location of events, rather than goods, since we will be particularly interested in the location of certain experiences. But nothing is intended to hang on this. 
the subjective probabilities of the events occurring, and holding fixed any other relevant factors (such as being given additional turkey drumsticks) the agent prefers $E$ over $E^{*}$. An agent is in fact negatively future-biased if with respect to two negatively valenced events $\mathrm{E}$ and $E^{*}$, where $E$ is located in the future, and $E^{*}$ is located in the past, and where $E$ and $\mathrm{E}^{*}$ are equally valuable to the self that experiences them, and adjusting for the subjective probabilities of the events occurring, and holding fixed any other relevant factors (such as being given additional turkey drumsticks) the agent prefers $\mathrm{E}^{*}$ over $\mathrm{E}$. This is to say that, holding fixed all the relevant factors, an agent is future-biased when she prefers positively valenced events be located in the future, and negatively valenced events in the past.

It has been thought that people exhibit future-biased patterns of preferences with regard to hedonic events: sensations, such as pleasures or pains, with some, such as Sullivan [1] (p 58) holding that we are future-biased, that "we assign no value to a merely past painful experience or pleasurable experience." Indeed, many philosophers have thought that not only are we future- biased (absolutely or otherwise) but that this pattern of preferences is rationally permissible (Prior [2], Hare [3,4], Kauppinen [5], Heathwood [6].

That we are future-biased was made especially vivid by Parfit [7]. He asked that we imagine certain situations and then declare our preferences. Here is one such situation. You are to imagine that you wake up in hospital suffering short-term, temporary, memory loss. You know that you have to undergo a painful operation, but you do not know if you are just waking up from the operation or if you are still to have it. You see a nurse approaching and you prepare to ask him whether you already had the operation. Would you prefer to learn that you already had the painful operation, or that you are still to have it? If you share Parfit's preference for learning that you have already had the painful operation, then (holding fixed the subjective probability of the operation occurring, and holding fixed its painfulness, and holding fixed any other relevant factors (such as for instance that the quality of the surgery was the same whenever you had it, that you are not being paid to have surgery on one date rather than another, and so on)) you exhibit negative hedonic future-bias.

Now imagine instead that you wake up feeling a little groggy, and for a moment cannot remember whether you are experiencing the after-effects of a truly awesome party, or instead the awesome party is to happen this evening. Would you prefer that the party is still to happen tonight, or that it was last night? If you share Parfit's preference that you learn that the party will be tonight, then (holding fixed the subjective probability of the party occurring, and holding fixed its pleasurability, and holding fixed other relevant factors (such as, for instance, whether there will be a fire on the premises when the party is underway; whether the neighbours will call the police to report a noise complaint; whether the kitchen will be damaged, (and so on)) you exhibit positive hedonic future-bias.

More generally, if, holding fixed all relevant factors you have this pattern of preferences, then you attach greater evaluative weight to pleasant and unpleasant experiences when they are in the future than when they are in the past. That is why you prefer negative events to be in the past, and positive events to be in the future.

Parfit [2] (p 173) appears to agree, at least regarding negative events. He writes "I do in fact regard my past suffering with complete indifference. I believe that, in this respect, most other people are like me". Others, such as Suhler and Callender [8] and Yehezkel [9] have thought that we non-absolutely discount the past: that we attach some value to past events, but that we discount the value of those events relative to future events.

Recent empirical work supports the contention that people are positively hedonically future-biased: they prefer that, holding fixed all relevant factors, positive hedonic events be located in the future rather than the past. It also shows that people are negatively hedonically future-biased: they prefer that, holding fixed all relevant factors, negative hedonic events be located in the past rather than the future (Caruso, Gilbert and Wilson [10] Greene, Latham, Miller and Norton [11]).

Contemporary work has focused both on whether future-bias is rationally permissible, rationally obligatory, or rationally impermissible. The focus has more frequently been on 
the question of whether it is rationally permissible ${ }^{2}$. It is this question to which this paper addresses itself.

Those who think that future-bias is at least rationally permissible often ground its permissibility in features of time itself. This trend started with Prior [2] who pointed out that we have temporally asymmetric attitudes-we are, for instance, relieved that (some) events are past, whereas we dread that (other) events are future-and he suggested that these asymmetric attitudes are both explained by, and rendered rationally permissible by, the structure of time.

In what follows Section 2 I consider a number of proposals for grounding the rational permissibility of future-biased preferences. I then consider these proposals in light of a number of time-travel scenarios. In Section 3, I argue that what time-travel teaches us is that grounding the permissibility of future-biased preferences in absolute pastness and futurity fails. In Section $4 \mathrm{I}$ argue that consideration of time-travel scenarios also shows us that grounding said permissibility in objective pastness and futurity likewise fails. I think the intuitions upon which I draw in these two sections are likely to be fairly robust and general. That is, I think you will share them. So, these two sections show that we have reason to think that if future-biased preferences are rationally permissible, they are not rendered rationally permissible by the structure of time itself. In the following two sections I consider two other proposals for grounding the rational permissibility of future-biased preferences. In each of these sections, I present still more cases, and rely on further intuitions. Section 5 considers the prospects for grounding the rational permissibility of future-bias in subjective pastness and futurity. Section 6 , considers the prospects for grounding the rational permissibility of future-bias in causal relevance. In each section I present cases, and elicit intuitions, that give us reason to think that neither subjective pastness/futurity nor causal relevance ground the rational permissibility of future-bias. However, here I have to put my hands up. I do not think that all of you will share the intuitions in question. So, what these sections show is that insofar as you share my intuitions in these cases, you have reason to think that we cannot ground the rational permissibility of future-bias in either of these features of the world. Ultimately though, I will happy if you come away from this paper having only been convinced of what I say in Sections 3 and 4.

\section{Grounding the Permissibility of Future-Biased Preferences}

Let us distinguish the absolute past/future from the objective past/future and from the subjective past/future.

Absolute Past/Future: An event, E, is in the absolute past iff E was in the metaphysically privileged present ${ }^{3}$. An event $\mathrm{E}^{*}$ is in the absolute future iff $\mathrm{E}^{*}$ will be in the metaphysically privileged present.

Objective Past/Future: An event, E, is in the objective past relative to an agent A located at temporal location $\mathrm{T}$, iff $\mathrm{E}$ is earlier than $\mathrm{T}$. An event, $\mathrm{E}^{*}$, is in the objective future relative to an agent $\mathrm{A}$ located at temporal location $\mathrm{T}$, iff $\mathrm{E}^{*}$ is later than $\mathrm{T}$.

Subjective Past/Future: An event, E, is in the subjective past of an agent, A, iff E is earlier, in the personal-time of A. An event $\mathrm{E}^{*}$ is in the subjective future of an agent, $\mathrm{A}$, iff $\mathrm{E}^{*}$ is later, in the personal-time of A.

Hence, $\mathrm{E}$ is absolutely past only if there is a metaphysically privileged present set of events, and E was metaphysically present, but is no more. To capture this I will often simply talk of $E$ being earlier than the metaphysically privileged present, but this is not intended to imply that $\mathrm{E}$ exists ${ }^{4}$. Mutatis mutandis, for $\mathrm{E}^{*}$ being in the absolute future.

2 See Prior [2], Hare [3,4]; Kauppinen [5], Heathwood [6] Pearson [12] and Dorsey [13] Brink [14], Greene \& Sullivan [15] Sullivan [1] and Dougherty [16,17] Hedden [18].

3 If $\mathrm{E}$ is extended it might be that some of $\mathrm{E}$ is still in the metaphysically privileged present even though the rest is absolutely past. We can say that $\mathrm{E}$ is completely absolutely past iff $\mathrm{E}$ was in the metaphysically privileged present, and is no longer. For most of the purposes of this paper I am interested in events that are completely absolutely past, but for simplicity I will just talk of events being absolutely past.

4 In case you think that relations like earlier-than are existence entailing, and this characterization is unfriendly to presentists. 
So, there are only absolutely past or future events in worlds in which time robustly passes: worlds in which some version of the A-theory is true and hence in which some events are in the metaphysically privileged present, and which events those are, changes.

By contrast, what is objectively past, or future, is always relative to a temporal location. So, this characterisation is consistent with a B-theoretic, or block universe, view of time on which past, present, and future events exist and are related by static earlier-than and laterthan relations, with no set of events being metaphysically privileged by being objectively present. Given a block universe view, pastness and futurity are not absolute notions: what is past relative to one event is future relative to another ${ }^{5}$.

Finally, the subjective past (or future) of agent A includes those events that are earlier (or later) in the personal-time of the agent in question. Here, I conceive of personal-time as Lewis [19] does. Roughly, then, personal-time is time as it is measured by the timetraveller. It is the time as measured by the wristwatch of the time-traveller but also, more generally, as measured by the contents of the time machine: the amount of food the traveller digests during the period, the amount of decay of particles in the time machine, and so on. Personal-time is what allows us to make sense of the idea that one can travel backwards in time 300 years, and do so via a journey that takes only 5 minutes. In such a case we have travelled 300 years in time, and have taken 5 minutes of personal-time to do so.

So, I assume that we can order a person's person-stages in terms both of their order in time and in terms of their order in personal-time. Suppose Freddie gets into a time machine and travels back 300 years in time, taking 5 minutes to do so. The person-stage that steps out of the machine will be earlier, in time, than the stage that steps into the machine. However, when we order Freddie's stages in terms of personal-time, we will say that the stage who steps out of the machine is later, in personal-time, than the stage that steps into the machine.

In the remainder of this paper I focus on what we can learn about future-bias by thinking about time-travel. In particular, I will focus on backwards time-travel: time-travel in which one travels to some past time. Perhaps there are also interesting lessons to be learned by considering forwards time-travel. That, however, is a project for another day.

First, then, a brief note on how I am thinking about backwards time-travel (henceforth just time-travel). I will suppose that $X$ travels backwards in time just in case $X^{\prime}$ 's departure from one time, $t$, is a cause of its being true that $X$ arrived at some earlier time, $t$-minus. So, in order to travel backwards in time it needs to be that the same person arrived at the destination as departs (where 'being the same person' might amount to the there being two person-stages that are stages of the same person), and its being true that the departure event caused it to be the case that $X$ existed at $t$-minus.

I frame things in this way in order to allow that the destination time might no longer exist at the departure time (if presentism is true, for instance). In such cases a person will count as time-travelling just in case it is, presently, the case that they did exist at some past time, and that their having existed at that past time causally depended on their getting into the machine in the present time ${ }^{6}$.

Finally, I assume that time-travel does not involve 'moving the present' in a way that 'undoes' reality. On some views of time-travel (such as that of van Inwagen [20]) in an A-theoretic world, it is not simply the case that a time-traveller always arrives at a time when it is present, but rather, that they take the present with them. I take the difference, here, to be that in the former case a time-traveller travels to a time when it is present (just as they travel to a time when it exists), while in the latter case the time-traveller 'picks up' the present and takes it with her, effectively rewinding time altogether, so that moments that were present but are no longer, cease to be such that they were present at all. So, on a growing block model, for instance, the time-traveller travels back in time and in doing so

5 Moreover, if you're worried about special relativity, you can suppose that some events are neither objectively past, nor future: these are the ones that relative to L are in the absolute elsewhere. You might think these are neither earlier, nor later, than L. Then you can think that everything in L's backwards light cone is objectively past relative to L, and that everything in L's forward light cone is objectively future relative to L.

6 Whether this really is time-travel is of course debated. 
deletes all of the block back to the moment at which they arrive. The block then re-grows from then onwards. In general, I think, most of what I say holds true regardless of how one is thinking about time-travel. Additionally, I will explicitly consider this view later in the paper. However, it is worth noting that this is not what I have in mind when I talk of time-travel, and perhaps sometimes this makes a difference to what I say.

\section{The Absolute Past}

Let us begin with a proposal for grounding the rational permissibility of discounting the value of past events, which appeals to those events being absolutely past. This proposal was probably first suggested by Prior [2] who argues that verbal expressions of timeasymmetric attitudes like relief require an irreducibly tensed semantics, which in turn implies (the speaker's belief in) a metaphysics of irreducibly tensed facts or properties ${ }^{7}$. One way to make sense of this idea is to suppose that the time-asymmetric nature of our attitudes grounds the rational permissibility of discounting the past, and, in turn, the rational permissibility of the asymmetry of those attitudes is grounded in there being irreducibly tensed facts. That is, it is rationally permissible to have different attitudes towards past events compared to future ones-regretting or feeling relief about past events, and anticipating or dreading future events-because the former are in the absolute past, and the latter are in the absolute future. In turn, there being these asymmetric attitudes renders it permissible to discount the value of past events relative to future ones.

A slightly different way to argue for the idea that it is rationally permissible to discount the value of absolutely past events goes via the thought that our experience or phenomenology of robust temporal passage ${ }^{8}$ grounds the rational permissibility of discounting the past (Schlesinger [21] Craig [22]). I will take it that the phenomenology of robust passage consists in the experience of a change in which events are in the metaphysically privileged present. It might also include the experience of future events coming progressively closer and of past events receding. Then, the idea may be that because events in the absolute past are moving away from us and those in the absolute future are moving towards us, it is rationally permissible to discount the value of the former relative to the latter.

As a matter of fact, neither of these suggestions strikes me as persuasive. First, it's not clear exactly why some events being absolutely past, and some absolutely future, grounds our having asymmetric attitudes towards those events. Second, it's not clear why, even if those attitudes are rationally permissible and are rendered rationally permissible by some events being absolutely past and some absolute future, that this in turn renders it rationally permissible to discount the value of past events. It does not obviously follow from the fact that we anticipate some event $\mathrm{E}$ when it is future and later feel relief that $\mathrm{E}$ is past, that we should discount the value of E when it is past, compared to when it is future. Why should the fact that we direct the attitude of relief towards an event mean that the event has less value than when we direct an attitude of anticipation towards it? Perhaps it does, but it certainly is not straightforwardly obvious why this should be. Third, even if we do experience future events as lying ahead of us and moving towards us, and past events as lying behind us and receding away from us, as Yehezkel [9] notes, it's hard to see why this would render it rationally permissible to devalue past events relative to future ones. Similar remarks are made by Parfit [7] (p. 178) and Hare [4], (pp 510-11), among others.

Nevertheless, let us begin with what I call the Unqualified Absolute Past Thesis. I call this the unqualified thesis since on this view it is rationally permissible to absolutely discount the value of past events.

Unqualified Absolute Pastness Thesis (UAPT): It is rationally permissible for A to absolutely discount the value of event $\mathrm{E}$, if $\mathrm{E}$ is absolutely past.

\footnotetext{
7 Prior's argument has been widely criticised.

8 I will talk of robust temporal passage to distinguish it from what is sometimes known as anodyne temporal passage, where this latter is consistent with a block universe view of time. Anodyne passage, on this view, is something like the succession of events. By contrast, robust passage consists in the changing of which events are absolutely present.
} 
In what follows I argue that by considering time-travelling scenarios we have good reason to conclude that UAPT is false. To show this, I will describe a series of scenarios and ask you to reflect on your own preferences in these cases, and I will hope that your preferences are roughly like mine. I will also ask you to reflect on which preferences you think are rationally permissible in these cases. That is, I will ask you to reflect on which preferences you think you should have, in these cases.

In doing so, I will suppose that each of us is able to ask ourselves not only what preference we in fact have, but also whether we think those are the preferences that we should have. So, I take it that in principle one could know of oneself that one would in fact prefer the greater pain in the past, to the lesser pain in the future. However, perhaps one also judges that this is not the correct preference to have, precisely because this is to prefer a state of affairs in which, overall, one is worse off.

In the following scenarios I ask that we reflect not only on what we prefer, but also on what preference we think we should have. I assume that our judgements about the rational permissibility of preferences provide some, albeit defeasible, evidence about the rational permissibility of those preferences. So, if we are inclined to judge that we should prefer $x$ to $y$, then I take it that this is defeasible evidence that it is not rationally permissible to prefer $y$ to $x$. It is, of course, only defeasible evidence since our intuitions might be mistaken.

Still, defenders of the rational permissibility of future-bias tend to appeal to these kinds of judgements and intuitions in defence of the permissibility of the relevant pattern of preferences. Moreover, they tend to appeal to the idea that it is the structure of time itself that gives rise to these judgements and ultimately vindicates them. So, I take it that such philosophers would find it worrying if, in the scenarios in question, the preferences we have, and think we should have, are not ones that tend to support the idea that futurebias, if rationally permissible, is made permissible by the structure of time. For these philosophers are precisely ones that take seriously the role of our judgements about the rational permissibility of certain preferences, in certain scenarios.

Further, I will take it that our preferences (mine, and yours dear reader) regarding when in time we would prefer some event to be located, provide defeasible evidence of people's preferences more generally in these cases. In an ideal world I would present you with empirical evidence about all of these cases. This world is not ideal. Still, there is evidence that is relevant, and along the way I will point to this. In addition, we have more general evidence about the extent to which in this domain, philosophers' own preferences mirror those of non-philosophers, and the extent to which philosophers' predictions about non-philosophers' preferences are correct.

So, let us quickly consider this general sort of evidence. That evidence suggests that philosophers' own first-personal preferences-that is, their preferences about where they would like events that they themselves will experience, to be located in time-are the same as non-philosophers' first-personal preferences, and, in turn, their predictions about nonphilosophers' preferences (which are made on the basis of their own preferences) turn out to be accurate. Using the sorts of scenarios described by Parfit [7] and Hare [4] philosophers predict that people will be hedonically positively and negatively future-biased. Those predictions are vindicated by empirical research (Greene, Latham, Miller and Norton [11]

There are really only two places where philosophers' predictions about non-philosophers' preferences (in these sorts of cases) have been shown to be inaccurate. The first is with regard to third-personal preferences: these are the preferences that we have over where in time someone else experiences some event. Philosophers predicted that third-personal preferences would be unlike first-personal preferences, in that they would fail to exhibit future-bias (Parfit [7] (p 181) Brink [14] (p 378-9), Greene and Sullivan [15] (p 968), and Dougherty [16] (p 3)). For instance, Parfit writes

"I am an exile from some country, where I have left my widowed mother. Though I am deeply concerned about her, I very seldom get news. I have known for some time that she is fatally ill, and cannot live long. I am now told something new. My mother's illness has become very painful, in a way that drugs cannot relieve. 
For the next few months, before she dies, she faces a terrible ordeal. That she will soon die I already knew. But I am deeply distressed to learn of the suffering that she must endure. A day later I am told that I had been partly misinformed. The facts were right, but not the timing. My mother did have many months of suffering, but she is now dead"

Parfit says that although he is deeply distressed about his mother's suffering, he has no preference regarding whether her suffering has already occurred and is now passed, or whether it is still to come. So, he thinks that in a third-person condition we will be indifferent about the location of hedonic events, in a way that we are not indifferent in a first-person condition.

This prediction is not borne out (Greene, Latham, Miller and Norton [11]). Instead, people's preferences about where in time other people's experience lie mirror their own preferences: that is, they also show future-bias. In this paper I focus only on first-person preferences. So, we can have some confidence that consideration of our preferences (you and I, dear reader) can give us some insight here.

Let us consider our first case.

Case 1:

You have access to a time machine that is able to take you backwards in time and deliver you to the past. The flight will take $2 \mathrm{~h}$ in your personal-time, and you will arrive 300 years into the past. You are not able to work the machine on your own, and you are given several options by 'Time-travellers Journeys', the company that owns the machine and runs time-travel journeys for profit. You can either depart for the past tomorrow, or you can depart the day after tomorrow. If you depart tomorrow, due to moderately elevated pressure in the time machine (which you will not notice during the flight) when you arrive 300 years in the past, one of the fillings in your tooth will have expanded and you will need emergency dental surgery. You will need to have that surgery in the past, since the time machine takes $24 \mathrm{~h}$ to re-power after a journey. That surgery will take $3 \mathrm{~h}$ and be very painful, since there were few anaesthetics 300 years ago and they used peddle-drills. So, the surgery will be very unpleasant and painful indeed. If you depart for the past the day after tomorrow, the pressure in the time machine will not elevate, and the filling in your tooth will remain where it is. When you arrive 300 years in the past you will not require dental surgery. Would you prefer to take the trip that departs tomorrow, or the trip that departs in two days' time?

Is it rationally permissible to prefer the trip that departs tomorrow, to the trip that departs in two days' time? Well it might be, if certain relevant factors were not held fixed. For instance, suppose that an assassin has been set on your tail and you have reason to believe that if you are around tomorrow the assassin will find you. Then, you would have strong reason to prefer the trip that departs tomorrow, despite the dental surgery involved. For that minimises your chances of being assassinated. Since we are interested in what might ground the rationality of future-biased preferences, not merely apparently future-biased preferences, though, let us hold fixed all these relevant factors.

Holding fixed these factors, my prediction is that both you and I would prefer to take the trip that departs in two days' time. Here is prediction number two: you and I both judge that it is not rationally permissible to prefer to take the trip that departs tomorrow. This gives us reason to think that UAPT is false. According to UAPT, since the painful dental procedure is absolutely past, it is permissible for you to absolutely discount its value. So, it is permissible for you to be indifferent between these two trips. That seems wrong.

Now, perhaps you think that backwards time-travel and robust temporal passage are inconsistent. One cannot travel back in time in any world in which time robustly passes. 
There are arguments to that conclusion. ${ }^{9}$ The best of these, to my mind, appeal to the fact that backwards time-travel requires retrocausation. However, one might argue, the change in which events are present is inextricably connected to the direction of causation. What it is for a set of events to change from being present to being past is for those events to bring it about that a new set of events is present, and they do this via some causal process. If so, the direction of causation must align with the direction of the flow of time. Hence, there can be no backwards causation in worlds with robust passage, and hence no backwards time-travel either. Others think that other considerations are more potent, such as the idea that if presentism is true, then there is nowhere to travel to. At best, one can make it the case that some past-tensed truth is the case: namely that one did exist at some earlier time (Sider [19]). However, one should not think that there is any sense in which one is about to travel anywhere (since the anywhere in question does not exist).

Regardless, if one thinks that robust passage is inconsistent with time-travel then two options present themselves. First, it might be that Case 1 is impossible. You will think this if you think that every world with time contains robust passage (i.e., a block universe world is impossible). Then, backwards time-travel is impossible. Alternatively, you might allow that block universes are possible, and hold that backwards time-travel occurs only in these worlds. However, in these worlds there is no absolute past or future. So, Case 1 must be describing a world that lacks an absolute past or future. Hence, it is not a counterexample to UAPT. In either case, Case 1 provides us with no reason to doubt that what grounds the rational permissibility of our discounting past events is that those events are absolutely past. (Of course, if you think that actually, there is no robust passage then UAPT is not going to be appealing since even if it does render it rationally permissible to discount the absolute past, there is actually no absolute past and so it does nothing to explain why our actual discounting of the past is rationally permissible, assuming that it is).

I do not want to adjudicate the issue of whether backwards time-travel is consistent with robust passage. Those who think it is should conclude that Case 1 gives us reason to think that UAPT is false. Indeed, it is worth noting here that if one conceived of passagefriendly time-travel as Van Inwagen [13] does, in terms of picking up and moving the present, then UAPT is especially puzzling. On that view of time-travel one basically 'deletes' all of the past up until the moment to which one travels. So, if it is now the case that Mother Theresa saved, let us say, 1500 lives, if I travel backwards to a time before she begins her good works, I start time from that moment. Then, there will no longer be any truths about those good works, and indeed, time might unfold in such a manner that she no longer performs any such works.

Philosophers have worried that if this were how time-travelled works, then this would raise some pretty hefty ethical issues about time-travelling ${ }^{10}$. For every time someone time-travels they wipe out many lives. However, if UAPT were correct then we should have no such worries. After all, what is being wiped out is all absolutely past. Yet, if backwards time-travel did work this way we surely should worry. So, this suggests that there is something wrong with UAPT.

I think that even those who hold that backwards time-travel is incompatible with robust passage should concede that Case 1 shows us something important. When we think about Case 1, the reason we are inclined to draw the conclusions we do-namely that it is not rationally permissible to prefer to travel tomorrow over the day after-is that the relevant event of the painful dental surgery is in the subjective future of the traveller. Even if this event takes place in the absolute past, as far as the traveller is concerned, they are events towards which one has the same forward-looking attitudes as one does towards events in the absolute future.

9 For arguments of this kind see Miller [23,24], Sider [25], Slater [26] and Hales [27]. For arguments to the conclusion that time-travel is consistent with robust passage see Monton [28], Daniels [29] Keller and Nelson [30] and Hall [31] and Van Inwagen [13] (though the kind of time-travel that is at issue in van Inwagen's case is rather different).

10 See for instance Bernstein [32]. 
Even if, as a matter of fact, the subjective past and absolute past cannot come apart because backwards time-travel is impossible, or is impossible in worlds that contain an absolute past, it seems clear that what is doing the work in this case is the subjective, rather than the absolute, location of these events. This tends to suggest that if something grounds the rational permissibility of discounting past events, it is not that they are absolutely past, but rather, that they are subjectively past.

This, of course, does not show us that UAPT is false. Perhaps what grounds it being rationally permissible to absolutely discount past events is that those events are subjectively past, and what grounds their being subjectively past is that they are absolutely past. Still, there is something uninformative about UAPT. If one thinks that there are worlds that fail to contain robust passage, then one will think that there are other grounds for the rational permissibility of discounting the past. For one will allow that there are worlds in which events are subjectively past, but not absolutely past, and that in those worlds what grounds the rational permissibility of discounting the past is those events being subjectively past.

What we wanted to know was what kind of thing renders discounting the past rationally permissible. In this event it seems right to say that it is that event being subjectively past. It is then a further question what grounds an event being subjectively past. Perhaps sometimes this is grounded by the event being absolutely past, and sometimes not. So, the maximally informative answer to our question - the thing that is really doing the normative heavy lifting - is the status of the event with respect to being subjectively past or future, not its status in being absolutely past or future.

There is also a more general problem with UAPT. Namely, it's very hard to see why the mere passage of time should render discounting the past rationally permissible. First, the mere passage of time does not seem to enshrine any sort of asymmetry between past and future that would license this normative stance. Presentism and the moving spotlight view, for instance, treat past and future events as sharing the same ontological status. So, that status cannot contribute to its being rationally permissible to differently value those events. While the growing block view holds that past events exist while future ones do not, it's hard to see how that asymmetry could do the work required either. Pre-theoretically, you might have thought that things would go the other way around: that we should more highly value those things that exist, over those that do not!

One suggestion at this point is that what grounds the rational permissibility of our preference for discounting the value of past events is indeed that they are absolutely past, but that this ground goes via the fact that events that are absolutely past have a different intrinsic character to those that are not.

In the last few years various dynamical theories of this kind have been articulated. For instance, some versions of the growing block view are ones on which the intrinsic property of some event E, when $\mathrm{E}$ is present, are different from its intrinsic properties when $\mathrm{E}$ is absolutely past. One notable view has it that there are no absolutely past phenomenal properties (Forrest $[33,34]$ ). Hence, there are no absolutely past pains: there are only events that were pains, when they were present. There are similar sorts of versions of other dynamical theories, on which absolutely past events/objects are non-concrete (Williamson [35]) or in which they lack ordinary properties such as height, weight, colour, and so on (Cameron [36]).

Suppose that agent $\mathrm{A}$ is absolutely present. Now consider some event $\mathrm{E}$ that is absolutely past. When E was present, E was painful for A. However, now that E is absolutely past $\mathrm{E}$ is not painful, and hence not painful for A. Since for the A-theorist what is true, simpliciter, is what is presently true, it follows that E is not painful, simpliciter. So, it makes good sense for A to attach no value at all to E.

Notice, though, that if this is how you think things are then you do not think that we exhibit future-biased preferences at all. Instead, you think that we exhibit merely apparently future-biased preferences. After all, if things are this way then everyone, including time-neutralists, will agree that we should locate negatively valenced events in the past, and positively valenced events in the future. 
Time-neutralists think that we should prefer that arrangement of events that maximises from a time-neutral perspective. That is, our preferences should not be sensitive to our representation of where in time events are located, though of course they should be sensitive to the intrinsic properties of the event, and the subjective probabilities that the event will occur. The time-neutralist will naturally recommend that we attach no value to past events if past events have no value. Or, to put things another way, on this view it is not that we discount the value of past events: rather, those events simply have no value, and this is the value we accord them.

So, if our world were like this, it would certainly explain, and indeed render rationally permissible (and surely obligatory) our having apparently future-biased preferences. However, UAPT would be doing no work here. Rather, something like the following would be true:

Intrinsic Value Thesis: It is rationally obligatory for A to value events at the value they have when evaluated in the absolute present.

Notice that IVT is not the thesis that we should value events at the value they had, when they were absolutely present. Rather, it is the thesis that we should value events at the value those events have, when evaluated at the absolute present.

The time-neutralist will accept this thesis (given that there is an absolute present). Then, if past events have no value, IVT entails that we will, and should be, apparently future-biased.

The point here, though, is that if things are this way then UAPT is false, and it is false because in fact we do not have future-biased preferences at all, and so of course the fact that events are absolutely past/future cannot be what renders those preferences rationally permissible. If UAPT is, as it were, in the running it has to be that we do in fact have future-biased preferences, and so it has to be that the intrinsic value of past events is no different from their intrinsic value when they were present. However, as we have just seen, when we make this assumption UAPT still does not look good.

Indeed, there are other reasons to find UAPT dubious. As a matter of fact, there is reasonable evidence that contrary to the predictions of those like Sullivan [1]) and Parfit [7] we do not absolutely discount past events (Greene, Latham, Miller and Norton [37,38]). While we do value past events less than future events, we do not entirely discount them. Make the past event sufficiently awful, and we will prefer a less awful future event over a more awful past event. This is not what we would expect if UAPT were true.

So, one option is that UAPT was implausibly strong to begin with. Perhaps we should only think that there being some difference between absolute past and absolute future events, makes it rationally permissible to non-absolutely discount past events. Call this the Absolute Pastness Thesis.

Absolute Pastness Thesis: It is rationally permissible for A to discount the value of event $\mathrm{E}$, when $\mathrm{E}$ is absolutely past.

If we look to Case 2, however, we can see that this is false.

Case 2:

You have access to a time machine that is able to take you backwards in time and deliver you to the past. The flight will take 2 hours in your personal-time, and you will arrive 300 years into the past. You are not able to work the machine on your own, and you are given several options by 'Time-travellers Journeys', the company that owns the machine and runs time-travel journeys for profit. You can either depart for the past tomorrow, or you can depart the day after tomorrow. If you depart tomorrow, when you arrive 300 years in the past, one of the fillings in your tooth will have expanded and you will need emergency dental surgery. You will need to have that surgery in the past, since the time machine takes 24 hours to re-power after a journey. That surgery will take 3 hours and be very painful, since there were few anaesthetics 300 years ago, and they used peddle-drills. So, the surgery will be very unpleasant and painful indeed. Fortunately though, 'Time-travellers Journeys' will make sure that 
you get back to the time machine for all your after-care needs, and will give you a very effective broad spectrum anti-biotic to prevent infection.

If you depart for the past the day after tomorrow, your filling will expand the day before you time-travel, and you will have the surgery then (tomorrow). Unfortunately, the one benefit of time-travel is that it makes fillings expand in a much less bad way. So, although if you have the surgery tomorrow you will have better technology, the underlying problem will be significantly worse. So, the surgery will still take 3 hours and be very painful. You can then travel 300 years into the past after the surgery is complete, where you will not require surgery.

You are assured that both surgeries carry the same risk of infection, complications, and future problems, and that both are equally painful.

Would you prefer to take the trip that departs tomorrow, or the trip that departs in two days' time?

Again, let us hold fixed other relevant factors in addition to those specified by the vignette, (such as the risk of infection, etc.). So, for instance, we should imagine that the amount of mental distress is the same whenever you have the surgery, (and so on).

Holding fixed these factors I predict that you, like me, are indifferent between these two options and that you think that we should be indifferent between these two options. However, if it were the case that it is rationally permissible to discount absolutely past events and if we did so discount, then we surely would and should prefer the option on which we have the surgery in the absolute past. For then the disvalue of the absolutely past surgery would be less than the disvalue of the absolutely future surgery. However, this seems wrong. So, we have reason to think that APT is false.

So far, then, we have reason to think that if future-bias is rationally permissible, it is not rendered rationally permissible by time having a particular metaphysical structure: a structure in which some events are absolutely past, and others are absolutely future. That does not mean that the structure of time is not doing the relevant work here though. Perhaps it is not this structure that matters. Perhaps instead what matters is that some events are objectively past, and others objectively future. It is this possibility that I consider in the next section.

\section{The Objective Past}

For each of the two theses we just considered that appeal to absolute pastness, we can instead appeal to objective pastness. Then, we end up with the following two theses:

Unqualified Objective Pastness Thesis (UOPT): It is rationally permissible for A to absolutely discount the value of event $\mathrm{E}$, when $\mathrm{E}$ is objectively past relative to $\mathrm{A}$.

Objective Pastness Thesis (OPT): It is rationally permissible for A to non-absolutely discount the value of event $\mathrm{E}$, when $\mathrm{E}$ is objectively past relative to $\mathrm{A}$.

The problem with each of these should be clear when we reconsider cases 1 and 2. In Case 1 you should prefer to take the trip that departs in two days' time (holding all relevant factors fixed). If so, we have reason to think that UOPT is false since the painful dental procedure is objectively past, and hence according to UOPT it is rationally permissible to prefer to take the trip that departs tomorrow. Likewise, Case 2 gives us reason to think that OPT is false. You should be indifferent between the two options. However, if OPT were true then it would be rationally permissible to discount objectively past events and hence to prefer the option on which you have the surgery in the objective past.

So, the very same considerations that led us to think that time having a dynamical structure does not ground the rational permissibility of future-bias also give us reason to think that time having an objective direction (there being objectively past, and future, evens) does not grounds its rational permissibility either. In sum, then, this suggests that it is not features of temporal structure itself that ground the rational permissibility of future-bias, assuming something does. It must be something else. What else could it be? In what follows I outline two possibilities and consider their plausibility. 


\section{The Subjective Past}

In this and the following section I consider two additional proposals for grounding the rational permissibility of future-bias: proposals that do not appeal to the structure of time itself. The primary aim of this paper is not to definitively argue that these proposals fail. Rather, I want to draw attention to the fact that matters are not quite as plain sailing as you might have thought. To do this I describe several more scenarios and elicit several more intuitions. I do not think that all of you will share all the intuitions I articulate. If you do, then you, like me, have reason to think that the features of the world I consider do not ground the rational permissibility of future-bias. If you do not share my intuitions, or you are unsure what intuitions to have, then for you these proposals remain live options. Still, I hope that you will at least see that there are some puzzles here that need to be overcome.

The first proposal I consider appeals to subjective past and future. It is easy to motivate this view. Why are our judgements different in Cases 1 and 2 than in ordinary cases such as those described by Parfit? In all three cases the relevant events are subjectively future even though sometimes those events are also absolutely or objectively past. That this difference is what matters might seem prima facie plausible, insofar as we might think that what matters is whether, from a subjective point of view, negative events are "over and done with" or not. Perhaps, then, it is rationally permissible to discount the value of subjectively past events. Since mostly, objectively past events are also subjectively past, it is easy to see why we might have confused the two. Call the first version of this thesis the Unqualified Subjective Pastness Thesis. On this view, it is rationally permissible to absolutely discount events that are in the subjective past.

Unqualified Subjective Pastness Thesis: It is rationally permissible for A to absolutely discount the value of event $\mathrm{E}$, when $\mathrm{E}$ is in $\mathrm{A}^{\prime} \mathrm{s}$ subjective past.

However, is this right? Consider Case 3.

Case 3:

You have access to a time machine that is able to take you backwards in time and deliver you to the past. You have a very vivid memory of being a young adult and having dental surgery that went on for about 3 hours and was very painful. Sometimes you just cannot shift the memory: the sound of the drill, the sensation in your mouth, the helplessness of sitting in the dental chair. The time-travel company you are journeying with 'Time-travellers Journeys' offers a new service. It allows you to change the past. Although it is, now, true that you did in fact undergo 3 hours of painful dental surgery, you can travel to the past and change what happened. In particular, the company will allow you to take special Nanobytes back to the past. You can deliver these Nanobytes to your younger self by surreptitiously putting them into a beverage drunk by your younger self. The Nanobytes will then fix your younger self's dental problems painlessly. You can either travel back to the time when you were a young adult, put the Nanobytes into your younger self's drink and change the past so that your painful dental procedure never occurs, or you can travel to that time and not put the Nanobytes in your younger self's drink, and hence leave the past as it has always been, as a past in which you underwent the painful dental surgery. You are reassured that if you change the past no other unfortunate or unforeseen consequences will occur. Do you prefer to travel back in time to change your painful dental procedure, or do you prefer to leave the procedure as it is?

Again, remember that we are holding fixed relevant factors.

At this point you might be thinking that changing the past is impossible. Set that thought aside (I will return to it shortly). My prediction is that if you are like me, you will prefer to travel back and change the painful dental procedure. ${ }^{11}$

Moreover, if you are like me you will think that it is not rationally permissible to prefer not to change the dental procedure. That is so even though the dental procedure is both

11 Of course, we don't need to appeal to time-travel here. Suppose that God could change the past. Then we can imagine that God simply asks you whether you want your past dental surgery to be changed or not. 
objectively and subjectively past. However, if it is permissible to absolutely discount events in the subjective past, then it is permissible to prefer not to change the dental procedure. So, this gives us reason to think that USPT is false.

At this point you might worry that what is really driving intuitions in Case 3 are the changes that would ensure to your (the protagonist's) subjective present and future. For instance, perhaps by changing the past with regard to my dental procedure I thereby bring it about that I no longer remember those awful events and that I am not longer afraid of the dentist. However, these are benefits that accrue to my current and future selves. So, perhaps my motivation for preferring to change the past is really still being grounded in the value I place on subjectively present and future experiences, rather than on the value I place on subjectively past ones.

To control for this possibility, we can reimagine Case 3.

Case 4 is just like Case 3, except that the time-travel company explains to you that although you can change whether or not you underwent the painful dental surgery, doing so will not change your current memories or affective attitudes. So, you will still have the same apparent memories as of undergoing the painful dental surgery. Indeed, you will still believe that you did undergo the surgery. It is just that this belief will be false, and the memories will be merely apparent. So, nothing about your subjective future or past will be altered if you change whether you underwent the painful surgery. With that in mind, do you still prefer to travel back and change the dental surgery? I am guessing that you do. Moreover, I am guessing that you think that this is the correct preference.

Even so, you might object to Cases 3 and 4 on the following grounds. Changing the past is impossible for precisely the reasons that Lewis [12] outlined. There are those who offer an account of changing the past on which the time we travel back to (and wish to change) is extended along some further dimension — the hypertemporal dimension-so that the original 'part' of the time remains as it ever was, and changing the past consists in making it the case that that time has another part in which things go differently (Goddu [39], Meiland [40]). On such a view times endure across the hypertemporal dimension, so that a time can be one way at one hypertemporal location, and a different way at some other hypertemporal location. Defenders of these models of changing the past insist that this is a perfectly good deserver of the moniker. Others argue that this is not changing the past at all: the original past is still there, all we have done is create some other location at which different things happen, than happen at the original locations (Baron [41]). If you take this latter view, then you will conclude that Cases 3 and 4 describe impossible scenarios.

However, one might think, our intuitions about impossible scenarios are not any kind of evidence about what is, or is not, rationally permissible. So, it would be nice if we could construct a case that is like this one but in which the scenario does not describe changing the past. I think we can. That is case 5 .

Case 5:

You have access to a time machine that is able to take you backwards in time and deliver you to the past. You have a very vivid memory of being a young adult and having dental surgery that went on for about 3 hours and was very painful. Sometimes you just cannot shift the memory: the sound of the drill, the sensation in your mouth, the helplessness of sitting in the dental chair. The time-travel company you are journeying with 'Time-travellers Journeys' offers a new service. It allows clients to travel to the past and insert false memories into their younger selves. You cannot imagine why anyone would buy such a service until your friend Freddie suggests to you that you travel back and insert a false memory as of having a painful 3 hours dental surgery when you were a young adult. You wonder why you would do that. Then, Freddie tells you that if you do, there is every reason to suppose that your current memory is in fact that false memory, and that you never really underwent that very painful surgery. Instead, Freddie suggests, perhaps you should travel back in time and give your younger self a special dentistry pill that releases Nanobytes that fix teeth quickly and painlessly. The time-travel company gives you two options. You 
can travel back without the technology to insert the false memory, and without the Nanobytes, or you can travel back in time with both pieces of technology. What do you choose?

To be clear, Case 5 is intended to be a case in which you can causally effect the past, but cannot change it. You are confident that whether or not you had the past painful dental procedure counterfactually depends on whether you travel back with the Nanobytes and false memory technology. If you travel back with these technologies then this will make it the case that you never had the painful procedure: you just seem to remember having it in virtue of the false memory technology. If you do not travel back with these technologies, then this will make it the case that you had the painful dental procedure. Suppose, too, that whether you in fact had the painful procedure in the past or you merely seem to remember doing so, will make no difference to your subjective future. You will not, for instance, come to fear dentists any less if you come to believe that the memory is merely apparent.

Do you choose to travel backwards with the technology or without it? My intuition in this case is that I would and should travel back with the technology, and I suspect I am not alone here. That is because if I travel back with the technology it is the case that I did not suffer 3 hours of painful dental procedure. Suppose for a moment that you take this view. Notice that the painful dental procedure is not only in the objective past; it is also in the subjective past. However, if it is rationally permissible to absolutely discount the value of subjectively past events, then it is permissible to prefer to travel back without the technology. If you think that this is not rationally permissible, then you should conclude that USPT is false.

Moreover, we can construct a similar case that offers a counterexample to the slightly weaker subjective past thesis, which says:

Subjective Pastness Thesis: It is rationally permissible for A to non-absolutely discount the value of event $\mathrm{E}$, when $\mathrm{E}$ is subjectively past relative to $\mathrm{A}$.

Here is that case.

Case 6:

You have signed up with Weird Psychology Tests ${ }^{\mathrm{TM}}$ in order to make enough money to afford fetta and avocado toast as well as a mortgage in Sydney. As part of the testing you undergo, you spent yesterday at the testing facility having experiences. You were told that when you awoke this morning you would have temporary amnesia about the nature of those experiences, but that your full memory will return in two days' time. Tomorrow, you will be asked whether you want to accept one unit of pain. The experimenters tell you that if you agree to the one unit of pain tomorrow, they will travel backward in time to yesterday and they will make it the case that your experiences yesterday were 6 units of pain. By contrast, if you decline the 1 unit of pain, tomorrow, they will make it the case that yesterday, you received 7 units of pain. So if you choose to decline the 1 unit of pain tomorrow, you will receive 7 units of pain in total, all located yesterday. If you choose to accept the 1 unit of pain tomorrow, you will receive 6 units of pain in total, 5 yesterday and 1 tomorrow. Do you choose to receive the 1 unit of pain tomorrow or not?

If you would choose to have the 1 unit of pain tomorrow, and if you judge that having the alternative preference is not rationally permissible, then you have reason to reject SPT. For tomorrow's pain is in the subjective future. Suppose you discount the 7 pains that are in the subjective past by, for example, 1 unit. Then, you will be comparing 6 units of past pain and no units of future pain, with 5 units of past pain and 1 unit of future pain. In that case it seems entirely rationally permissible to be indifferent between the two outcomes. If you think that you should prefer to accept the one future pain, this suggests that it is not rationally permissible to non-absolutely discount events in the subjective past, and that SPT is false.

Here, I think, intuitions are going to vary. So, this case might not provide you with reason to be suspicious of SPT. After all, my intuitions here are in stark contrast to that of Dorsey [13]. He writes that our inability to affect the past 'makes little difference. One 
might simply imagine that it is, in fact, possible to change (causally speaking, that is) the past-by some sort of time-travel machine or the hotline to God. Few would opt for the choice to take the less painful surgery today in order to correct the ten-hour surgery yesterday' [13] (p. 1910). So, I take it that Dorsey, at least, thinks that we will not prefer to accept the one future pain (indeed, he thinks we would not accept a less painful surgery to avoid a $10 \mathrm{~h}$ long surgery yesterday).

In fact, there is some empirical evidence we can appeal to here. First, there is evidence about people's preferences in conditions in which the past is not causally relevant. Following Parfit's [7] (p 165) famous My Past or Future Operations case, Greene, Latham, Miller and Norton [37] used a past-to-future ratio of 10:1 where participants reported whether they would prefer some amount of future pain or ten times as much past pain. They found that a majority of people preferred the ten units of past pain (though notably a majority is not everyone: $\sim 18 \%$ had the other preference). Interestingly, though, they found the opposite pattern of preference when it came to positively valenced events. When presented with one unit of future pleasure versus ten units of past pleasure, a significant majority of participants ( $65 \%)$ preferred the greater pleasure in the past. In follow up work Greene, Latham, Miller and Norton [38] found that although a majority of people prefer 10 units of past pleasure to 1 unit of future pleasure, they prefer 1 unit of future pleasure to 2 units of past pleasure.

These studies show that although people discount the past, they do not discount it absolutely. Still, they also tend to suggest that perhaps Dorsey is right, and people will not prefer tomorrow's less painful operation over yesterday's more painful one. That suggests that people will not think it rationally impermissible to prefer not to have the painful experience tomorrow, contra my prediction.

There is some evidence about this issue too. Latham, Miller, Norton and Tarsney [42] ran a study that presented participants with a vignette that is much like the case described in Case 6. In that vignette people who told that if they chose on additional shock in the future they would have been given 9999 shocks in the past (for a total of 10,000 shocks), but if they choose not to take the additional future shock they should have been given 10,001 shocks in the past, for a total of 10,001 shocks. This study found that the amount of future-bias diminished in the condition in which people could choose whether or not to take the additional shock, as opposed to a condition in which they were merely asked their preference regarding where in time the shocks would be located. So, causal relevance does make a difference, contra Dorsey [13].

Still, that study did not find that a majority of people decided to take the additional shock, which is contrary to the prediction I just made about Case 6. There are some features of the vignette used in that study that make me think that people's judgements in Case 6 might be less future-biased. First, the subject of the vignette does not have temporary amnesia; they simply lost track of how many times they were shocked in the past. That plays into the fact that the number of shocks is very high, and one might reasonably think that shocks have a diminishing marginal disvalue: that the difference between 9999 shocks in the past, and 10,001 shocks in the past might be effectively nothing, since perhaps the extra two shocks do not make a noticeable difference (on the back of 9999 shocks). However, if there is no noticeable difference between 9999 and 10,001 past shocks, then since the extra future shock will make a noticeable difference, it makes good sense to refuse the extra shock.

I think that a study in which the number of past shocks was much smaller, so that there is an obviously noticeable difference between the number of shocks you get in the past if you accept the additional shock, and the number you get if you do not, would make a difference here. However, of course, this is empirical speculation. What we can say is that if you share my intuitions about Case 6, then you will have reason to reject SPT. 


\section{Causal Relevance}

You might be thinking that all of these cases have something in common. In each case the past event is causally relevant to the preference. In Cases 2 and 3 the past is straightforwardly causally relevant, in that which preference you have determines which choice you make, and your choice is causally efficacious with respect to the relevant past events. The same is true in Case 5. If you prefer that you did not undergo painful surgery, then this preference will lead you to choose to travel back in time with the appropriate technology, and that choice is causally efficacious with respect to the relevant past events. In Case 6 your decision as to whether to accept the single unit of pain tomorrow determines how much pain you experienced yesterday. So, the past event is causally relevant to your decision. This suggests an alternative principle according to which what matters is whether or not an event is causally relevant to your preference.

Causal Relevance Thesis: It is rationally permissible for A to discount the value of event $\mathrm{E}$, when $\mathrm{E}$ is causally irrelevant to $\mathrm{A}$.

The rough idea is this. It is permissible to attach less weight to events that are causally irrelevant. The idea is that if we cannot causally affect some event, then nothing we can do will count for or against a choice with respect to that event. This idea was perhaps first suggested by Hume, who writes that the greater effect of future events than past events on the will is easily accounted for. As none of our actions can alter the past, 'tis not strange it shou'd never determine the will' (Hume [43] (Section 2.3.7.6). ${ }^{12}$ More recently, Kauppinen [5] has argued that our future-biased preferences are rationally justified by the fact that they have no effect on our choices. ${ }^{13}$ Our inability to affect the past also underlies an evolutionary explanation for future-bias suggested by Parfit [7] (p. 186) and Horwich [44] (pp. 194-196) and developed by Maclaurin \& Dyke [45] and Suhler \& Callender [8].

There is also reason to think this proposal plausible. Greene, Latham, Miller and Norton [46] found evidence that when people are brought to think more agentively about the relevant preference (i.e., to conceive of it more as a choice, rather than a preference) future-biased preferences are significantly decreased (indeed, the study found that people became past-biased under these conditions). That is at least consistent with the idea that future-bias decreases in conditions in which we take ourselves to have choices, where having a choice requires that the relevant events over which we are choosing be causally relevant.

This kind of reasoning would seem to suggest that it is rationally permissible to absolutely discount past events when these events are (as they often are) entirely causally irrelevant to the agent.

The problem is that CRT is not very plausible. Suppose God were to appear to you and tell you that there is some future event E, and that E is special in the following way: it does not matter what happens now, or at any time prior to E, God has made it the case that E will occur regardless. It is not simply that E will happen, and hence that whatever you in fact do, E happens. This is not merely a case of meeting death in Damascus. Rather, it is that, counterfactually, whatever you did, it would have been the case that E happened. So, $\mathrm{E}$ is causally irrelevant to your choices: whatever choices you make, these choices make no difference to the occurrence of $\mathrm{E}$.

Suppose, further, that although God knows which event E is, he will tell you only the following: either $\mathrm{E}$ is an event that will bring you great pleasure, or $\mathrm{E}$ is an event that will

12 Though this passage is often quoted to associate Hume with the practical irrelevance explanation for future bias, this is probably a mistake: Hume is here talking specifically about effects on the will, and the next sentence reads: 'But with respect to the passions, the question [of what explains 'the superior effects of the same distance in futurity above that in the past'] is yet entire, and well worth the examining' (Hume [43] 2.3.7.6; emphasis added). In trying to account for the past-future asymmetry with respect to the passions, Hume entertains a number of hypotheses, including a version of the temporal metaphysics hypothesis (2.3.7.9), but does not seem to take the practical irrelevance of the past as an explanation for its weaker effect on the passions.

13 Kauppinen does not claim that our past-directed preferences are always practically inert in the relevant sense. But he holds that when a future-biased preference would influence the agent's choices, or would contradict an earlier preference on which she has already based a choice, future bias is rationally impermissible, and moreover is no longer psychologically typical. 
bring you great pain. Now, although there is nothing you can do to determine whether $\mathrm{E}$ is the event that will bring you great pleasure, or great pain, it still seems clear that you can have a preference regarding which event $E$ is. Namely you prefer that $E$ is an event that brings you great pleasure. Moreover, it does not seem that you will discount the value of $\mathrm{E}$ despite it being the case that $\mathrm{E}$ is causally irrelevant to your choices.

Suppose you know that the disvalue of $\mathrm{E}$, if $\mathrm{E}$ is the painful event, will be minus 200, and you know that the value of $\mathrm{E}$ if $\mathrm{E}$ is the pleasurable event, be plus 200. There is also some other event, $E^{*}$. $E^{*}$ is an event that is causally relevant to your choices: you can either bring about $E^{*}$, or not. $E^{*}$ is worth plus 199. Now suppose that your friend Annie asks you whether you prefer $\mathrm{E}^{*}$ over $\mathrm{E}$, conditional on $\mathrm{E}$ being positive. I predict that, conditional on $\mathrm{E}$ being positive, you prefer $\mathrm{E}$ over $\mathrm{E}^{*}$, and that you will judge that any other preference is rationally impermissible. However, if it is rationally permissible for you to discount the value of $E$ because it is causally irrelevant, then the value of $E$ will fall below the value of $E^{*}$, and you should prefer $E^{*}$. So, this suggests that we do not think it is rationally permissible to devalue E, even though it is causally irrelevant.

Again though, perhaps you do not share my intuitions here. If so, you do not have reason to think that CRT is false.

\section{Conclusions}

What have we learned from all this? First, if it is rationally permissible to discount the value of past events then that permissibility does not issue from the structure of time itself. It does not issue from the fact that time robustly passes, (if it does), nor from the fact that some events are objectively past, (or future) relative to others. Perhaps the fact that some event is objectively, or absolutely, past often correlates with some other properties of that event, in virtue of which it is permissible to discount the value of that event. However, if so, it is these other properties that are doing the normative work, not the location of that event in time.

Two candidates that would fall into that category are the causal relevance of an event, and its location in personal time. Generally speaking, past events are both causally inaccessible and lie in the subjective past, while future events are causally accessible and lie in the subjective future. While I think that each of these plays some role in our preferences, if you share my intuitions about these cases, you should conclude that there is reason to think that neither is sufficient to render it rationally permissible to discount the past. That leaves open that these factors, perhaps in conjunction with some other factor(s) do the normative work here, or that there is no normative work to be done, because in fact it is not rationally permissible to discount the value of past events. If, on the other hand you do not share my intuitions in these cases then it might be that you have reason to think that one (or both) of these principles is correct. Perhaps then your task is to try to explain why it is that people like me have contrary intuitions.

Funding: This research was funded by ARC (Australian Research Council) grant number DP180100105 and FT170100262.

Conflicts of Interest: The author declares no conflict of interest.

\section{References}

1. Sullivan, M. Time Biases; Oxford University Press: Oxford, UK, 2018.

2. Prior, A.N. Thank Goodness That's Over. Philosophy 1959, 34, 12-17. [CrossRef]

3. Hare, C. Self-Bias, Time-Bias, and the Metaphysics of the Self and Time. J. Philos. 2007, 104, 350-373. [CrossRef]

4. Hare, C. A Puzzle about Other-Directed Time-Bias. Australas. J. Philos. 2008, 86, 269-277. [CrossRef]

5. Kauppinen, A. Agency, Experience, and Future Bias. Thought A J. Philos. 2018, 7, 237-245. [CrossRef]

6. Heathwood, C. Fitting Attitudes and Welfare. Oxf. Stud. Metaethics 2008, 3, 47-73.

7. Parfit, D. Reasons and Persons; Oxford University Press: Oxford, UK, 1984.

8. Suhler, C.; Callender, C. Thank Goodness That Argument Is Over: Explaining the Temporal Value Asymmetry. Philos. Impr. 2012, 12, 1-16.

9. Yehezkel, G. Theories of Time and the Asymmetry in Human Attitudes. Ratio 2014, 27, 68-83. [CrossRef] 
10. Caruso, E.; Gilbert, D.T.; Wilson, T.D. A Wrinkle in Time: Asymmetric Valuation of Past and Future Events. Psychol. Sci. 2008, 19, 796-801. [CrossRef]

11. Greene, P.; Latham, A.J.; Miller, K.; Norton, J. Hedonic and non-hedonic bias towards the future. Australas. J. Philos. 2020 [CrossRef]

12. Pearson, O. Appropriate Emotions and the Metaphysics of Time. Philos. Stud. 2018, 175, 1945-1961. [CrossRef]

13. Dorsey, D. Prudence and Past Selves. Philos. Stud. 2018, 175, 1901-1925. [CrossRef]

14. Brink, D.O. Prospects for Temporal Neutrality. In The Oxford Handbook of Philosophy of Time; Callender, C., Ed.; Oxford University Press: Oxford, UK, 2011; pp. 353-381.

15. Greene, P.; Sullivan, M. Against Time Bias. Ethics 2015, 125, 947-970. [CrossRef]

16. Dougherty, T. Future-Bias and Practical Reason. Philos. Impr. 2015, 15, 1-16.

17. Dougherty, T. On Whether to Prefer Pain to Pass. Ethics 2011, 121, 521-537. [CrossRef]

18. Hedden, B. Reasons Without Persons: Rationality, Identity, and Time; Oxford University Press: Oxford, UK, 2015.

19. Lewis, D. The Paradoxes of Time Travel. Am. Phil. Q. 1976, 145-152.

20. van Inwagen, P. Changing the past. In Oxford Studies in Metaphysics; Dean, Z., Ed.; Oxford University Press: Oxford, UK, 2010; Volume 5, pp. 3-28.

21. Schlesinger, G. The stillness of time and philosophical equanimity. Philos. Stud. 1976, 30, 145-159. [CrossRef]

22. Craig, W.L. Tensed time and our differential experience of the past and future. South. J. Philos. 1999, 37, 515-537. [CrossRef]

23. Miller, K. Time-travel and the open future. Disputatio 2005, 1, 223-232. [CrossRef]

24. Miller, K. Backwards causation, time, and the open future. Metaphysica 2008, 9, 173-191. [CrossRef]

25. Slater, M. The necessity of time-travel (on pain of indeterminacy). Monist 2005, 88, 362-369. [CrossRef]

26. Hales, S.D. No time-travel for presentists. Logos Epistem 2010, 1, 353-360. [CrossRef]

27. Sider, T. Traveling in A- and B-time. Monist 2005, 88, 329-335. [CrossRef]

28. Monton, B. Presentists can believe in closed timelike curves. Analysis 2003, 63, 199-202. [CrossRef]

29. Daniels, P. Back to the Present: Defending Presentist Time Travel. Disputatio 2012, 4, 469-484. [CrossRef]

30. Keller, S.; Nelson, M. Presentists should believe in time-travel. Australas. J. Philos. 2001, 79, 333-345. [CrossRef]

31. Hall, T. In Defense of the Compossibility of Presentism and Time-travel. Logos Epistem. 2014, 2, 141-159. [CrossRef]

32. Bernstein, S. Time Travel and the Movable Present. In Being, Freedom, and Method: Themes from the Philosophy of Peter van Inwagen; Keller, J., Ed.; Cornell University Press: Ithaca, NY, USA, 2017; pp. 80-94.

33. Forrest, P. The read but deal past: A reply to Braddon-Mitchell. Analysis 2004, 65, 358-362. [CrossRef]

34. Forrest, P. Uniform Grounding of Truth and the Growing Block Theory: A Reply to Heathwood. Analysis 2006, 66, 161-162. [CrossRef]

35. Williamson, T. Necessary Existents. In Royal Institute of Philosophy Supplement; O'Hear, A., Ed.; Oxford University Press: Oxford, UK, 2002; pp. 233-252.

36. Cameron, R. The Moving Spotlight: An Essay on Time and Ontology; Oxford University Press: Oxford, UK, 2015.

37. Greene, P.; Latham, A.J.; Miller, K.; Norton, J. (ms1) On Preferring that Overall, Things are Worse: Future-Bias and Unequal Payoffs. Available online: https:/ / philpapers.org/rec/GREOPT-2 (accessed on 31 March 2021).

38. Greene, P.; Latham, A.J.; Miller, K.; Norton, J. (ms2) How Much do We Discount Past Pleasures? Available online: https: //philpapers.org/rec/GREHMD-4 (accessed on 31 March 2021).

39. Goddu, G.C. Time-travel and Changing the Past: (Or How to Kill Yourself and Live to Tell the Tale). Ratio 2003, 16, 16-32. [CrossRef]

40. Meiland, J.W. A Two-Dimensional Passage Model of Time for Time-travel. Philos. Stud. 1974, 26, 153-173. [CrossRef]

41. Baron, S. Back to the Unchanging Past. Pac. Philos. Q. 2017, 98, 129-147. [CrossRef]

42. Latham, A.J.; Miller, K.J.; Norton, J.; Tarsney, C. Future Bias in Action. Synthese 2020. [CrossRef]

43. Hume, D. A Treatise of Human Nature; Oxford University Press: Oxford, UK, 1738.

44. Horwich, P. Asymmetries in Time: Problems in the Philosophy of Science; MIT Press: Cambridge, MA, USA, 1987.

45. Maclaurin, J.; Dyke, H. Thank Goodness that's Over': The Evolutionary Story. Ratio 2002, 15, 276-292. [CrossRef]

46. Greene, P.; Latham, A.J.; Miller, K.; Norton, J. Why are People So Darn Past-Biased? In Temporal Asymmetries in Philosophy and Psychology; Hoerl, C., McCormack, T., Fernandes, A., Eds.; Oxford University Press: Oxford, UK, 2021. 